\title{
Avaliação do Desempenho dos Fundos Long-Şhort no Brasil
}

\author{
Fábio Augusto Reis Gomes* \\ Vicente Cresto**
}

\section{Resumo}

Fundos Long-Short deveriam ter a capacidade de prover retornos positivos, superiores ao custo de oportunidade e independentes das condições de mercado, uma vez que podem possuir posições tanto compradas, quanto vendidas. Por esta razão, o presente artigo tem o objetivo de analisar os fundos Long-Short no Brasil, avaliando se clientes desses produtos estão simplesmente comprando retornos de mercado (Beta), ou se existe realmente geração de excesso de retorno (Alpha) independente dos retornos do mercado acionário. Analisando uma amostra de 76 fundos no período de 2 de janeiro de 2001 até 31 de março de 2008, com dados diários e mensais, encontram-se evidências de que poucos fundos conseguem gerar excesso de retorno. Há também uma evidência de que o excesso de retorno não é persistente. Finalmente, há pouca ou nenhuma evidência a favor de market timing.

Palavras-chave: fundos de investimentos; hedge funds; long-short; avaliação de desempenho.

Códigos JEL: G10; G23; G24

\begin{abstract}
Long-Short Funds should be able to provide positive returns, above the opportunity cost and independent of market conditions, once they can have both long and short positions. For this reason, this study aims to evaluate the Long-Short funds in Brazil, assessing whether customers of these products are buying just market returns (Beta), or if there is excess return (alpha) independent of the stock market. Analyzing a sample of 76 funds from January 2, 2001 to March 31, 2008, using daily and monthly data, we found evidence that a small number of funds are able to generate excess return. Besides, this excess does not exhibit persistence. Finally, there is little or no evidence for market timing
\end{abstract}

Keywords: mutual funds; hedge funds; long-short; performance evaluation.

Submetido em outubro de 2009. Aceito em julho de 2010. O artigo foi avaliado segundo o processo de duplo anonimato além de ser avaliado pelo editor. Editor responsável: Ricardo P. C. Leal. Os autores agradecem a Ricardo Brito e Luiz Felipe Andrade pelas sugestões e aos pareceristas anônimos pelos comentários, isentando-os de quaisquer erros remanescentes.

*Insper Instituto de Ensino e Pesquisa, São Paulo, Brasil. E-mail: FabioARG@insper.org.br

**Insper Instituto de Ensino e Pesquisa, São Paulo, Brasil. E-mail: vicentecresto@uol.com.br 


\section{Introdução}

A indústria de fundos tem crescido de forma impressionante nos últimos anos no Brasil. Conforme ilustrado na figura 1, em 1998 o patrimônio total da indústria era inferior a 400 bilhões de reais. Dez anos depois, em 2008, esse volume chegava a quase 1,2 trilhões de reais. Existem diversos tipos de fundos no Brasil e todos são classificados de acordo com a Associação Nacional dos Bancos de Investimentos (ANBID). ${ }^{1} \mathrm{Um}$ dos segmentos que apresentou um crescimento especialmente acentuado foi o de fundos Multimercados, como os Hedge Funds são classificados no Brasil. Enquanto a indústria de fundos cresceu, segundo dados da ANBID, um pouco mais de três vezes desde dezembro de 1997 até março de 2008, o patrimônio de fundos Multimercados aumentou quase doze vezes no mesmo período. Em 1998 esse tipo de fundo era apenas 6\% da indústria, no entanto, os fundos Multimercados do Brasil já correspondiam a $22 \%$ do total da indústria em 2008, conforme ilustrado na figura 2.

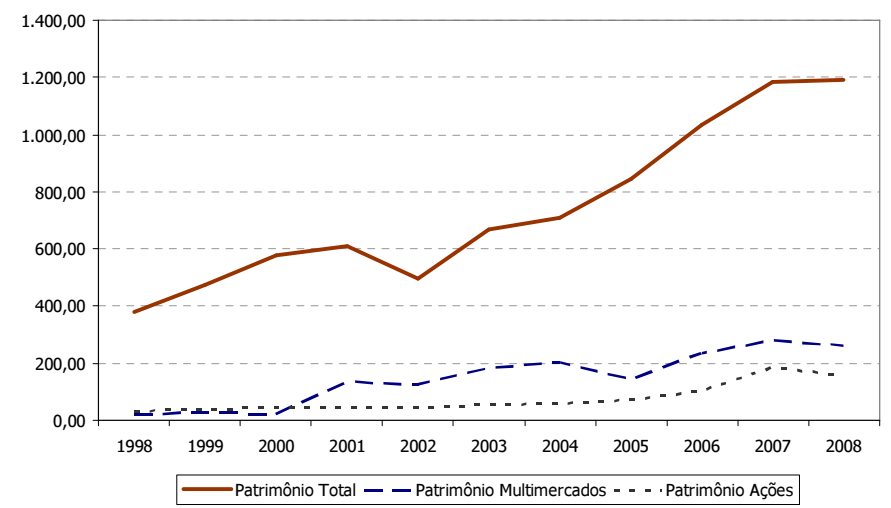

Fonte: ANBID.

Figura 1

Evolução da indústria de fundos (em bilhões de R\$)

No Brasil, apesar dos Hedge Funds serem classificados como fundos Multimercados, nem todos os fundos Multimercados podem ser considerados Hedge Funds. Muitas instituições e gestores utilizam-se da classificação Multimercados apenas para obter uma facilidade de regulamentação, uma vez que essa classificação é a mais abrangente possível. O escopo desse trabalho está concentrado nos Hedge Funds, assim, para iniciar o trabalho é necessário definir o que pode ser considerado um Hedge Fund. $\mathrm{O}$ termo Hedge Fund é muito genérico e não existe uma definição formal do mesmo, o que dificulta o processo de classificação dos

\footnotetext{
${ }^{1}$ A ANBID integrou suas atividades com a ANDIMA em 2009, criando a ANBIMA.
} 
fundos. Contudo, Anson (2006) apresenta uma definição ampla segundo a qual: Hedge Funds seriam veículos de investimentos privados para gerenciar carteiras concentradas de títulos públicos e privados, e seus respectivos instrumentos de derivativos, que podem possuir posições tanto compradas quanto vendidas e podem utilizar alavancagem. Já a ANBID classifica os fundos multimercados de acordo com a sua estratégia ou estilo, sem uma definição geral. Finalmente, vamos considerar nesse trabalho como Hedge Fund todo o fundo que utiliza posições compradas e vendidas em qualquer mercado, por meio de títulos e instrumentos de derivativos, e podem utilizar alavancagem.

Os Hedge Funds, principalmente no exterior, são classificados em diversas categorias e estilos: Macro, Crédito, Multiestratégia, etc. Uma categoria, ou uma subclasse dos Hedge Funds, seriam os fundos Long-Short de Ações. Os fundos Long-Short de Ações seriam fundos que teriam como principal estratégia utilizar posições, tanto compradas (Long), como vendidas (Short) em ações de empresas e índices de ações, tanto no mercado à vista, quanto no mercado de derivativos, para rentabilizar suas carteiras. A ANBID classifica os fundos multimercados LongShort como fundos que fazem operações de ativos e derivativos ligados ao mercado de renda variável, montando posições compradas e vendidas.
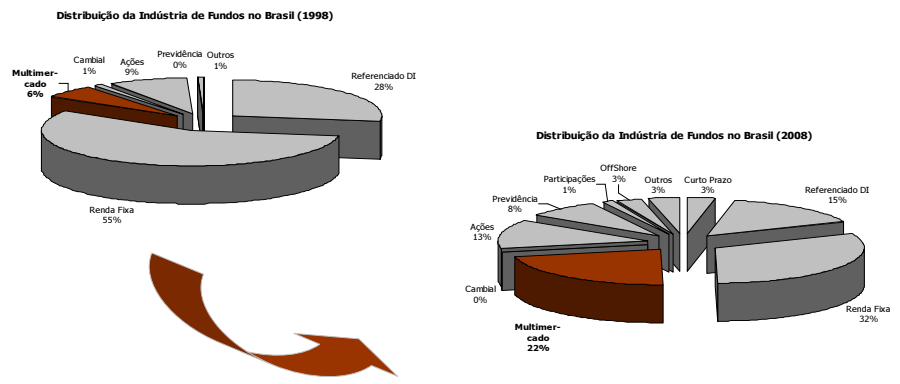

Fonte: ANBID

Figura 2

Evolução da distribuição da indústria de fundos no Brasil

Os Hedge Funds teriam a capacidade de gerar ganhos positivos, reduzir riscos, dada a possibilidade de atuar em diferentes mercados, e prover retornos não correlacionados com classes de ativos tradicionais como renda fixa e bolsa. Ou seja, deveriam ser capazes de prover retornos superiores ao custo de oportunidade em quaisquer condições de mercado. Ao longo deste trabalho vamos nos referir a Beta $(\beta)$ como o retorno gerado através de risco de mercado, ou seja, a exposição em relação ao mercado. Por sua vez, Alpha $(\alpha)$ é o excesso de retorno obtido, geralmente através de uma melhor escolha dos ativos ou uma melhor determinação de quando alocar em determinado ativo, o que Treynor e Mazuy (1966) definiram como market timing, inserindo um novo componente no modelo CAPM. 
Os fundos Long-Short, sendo definidos como uma subclasse dos Hedge Funds, também deveriam ser capazes de gerar retornos superiores ao custo de oportunidade sem correlação com o mercado. A diferença entre fundos Long-Short e fundos tradicionais de bolsa é que eles podem manter posições vendidas em ações que o gestor considerar que não terão bom desempenho, além de poder alavancar suas posições, isto é, ter uma exposição maior do que o seu patrimônio alocado nas diferentes estratégias. Essas diferenças deveriam criar um ambiente no qual gestores de fundos Long-Short fossem capazes de prover excesso de retorno.

Dado o crescimento recente da indústria de fundos Multimercados no Brasil, um questionamento que se levanta é se esses fundos realmente conseguem prover retornos superiores para atrair tantos investidores. Assim, esse trabalho tem como objetivo avaliar o desempenho dos fundos Long-Short no Brasil, analisando se realmente eles conseguem prover retornos superiores, sem exposição ao mercado. Para tanto, foram selecionados mais de 76 fundos e a análise foi realizada do período de 2 de janeiro de 2001 até 31 de março de 2008, com dados diários e mensais.

A metodologia econométrica utilizada consiste na estimação dos modelos por meio do Método dos Momentos Generalizados (GMM). Após as regressões, utilizando o modelo CAPM, verificamos como os retornos de mercado explicam os retornos dos fundos e se os fundos conseguem prover retornos superiores significativos. Em seguida, acrescentamos mais um componente ao modelo CAPM e dessa forma desmembramos o excesso de retorno em seletividade e market timing (Merton, 1981, Henriksson e Merton, 1981). Portanto, analisamos se os gestores possuem habilidade de market timing, havendo uma assimetria do fundo em relação ao mercado. Esta alteração do CAPM é importante, pois a omissão do termo de market timing pode causar viés nas estimativas do Beta. Encontram-se evidências de que apenas alguns fundos Long-Short no Brasil conseguem capturar excesso de retorno, dependendo do período analisado. Além disso, há pouquíssima ou nenhuma evidência a favor de market timing. Por fim, a análise de persistência indicou que, em geral, os fundos não geram excesso de retorno com essa característica.

Além desta introdução, o artigo está organizado da seguinte forma. A segunda seção apresenta a revisão bibliográfica. A terceira seção descreve a base de dados bem como a metodologia econométrica. Em seguida, são apresentados os resultados tanto para dados diários quanto mensais. Além disso, avaliamos a persistência do excesso do retorno nos fundos e comparamos os desempenhos dos fundos geridos por Gestores Independentes e por Bancos Múltiplos. A última seção apresenta as conclusões. Detalhes sobre os fundos estudados são apresentados no apêndice.

\section{Revisão Bibliográfica}

A indústria de Hedge Funds é ainda uma indústria recente e em desenvolvimento comparada à indústria de fundos tradicionais. Assim, só a partir da última década é que trabalhos dedicados a esse assunto começaram a ser publicados (Liang, 1998, Ineichen, 2002, Schneeweis et alii, 2003, Fung e Hsieh, 2004). Os 
estudos para o Brasil ainda são poucos e recentes, inclusive em virtude da indisponibilidade dados. Contudo, a literatura que fundamenta todos os estudos nessa área data de muito antes do desenvolvimento dessa indústria. Os alicerces que fundamentaram os estudos nessa área foram criados por Markowitz (1952) e por Sharpe (1964). Markowitz (1952) relaciona risco e retorno esperado de um portfólio de ações, criando assim o que chamamos de Fronteira Eficiente. Esse foi um dos primeiros estudos que focavam em construção de carteiras e não simplesmente em seleção de ativos individualmente, demonstrando que carteiras diversificadas eram mais eficientes do ponto de vista da relação risco e retorno.

Na década de 50, os computadores não eram tão eficientes, não possuíam tanta capacidade de processamento e eram extremamente caros, logo calcular diversas otimizações de carteiras não era trivial. Assim, Sharpe (1964) desenvolveu um modelo simplificado, cujo ponto principal é argumentar que os retornos das ações são relacionados com um fator comum, o que depois seria chamado de carteira de mercado. Com esse procedimento não seria necessário o cálculo de diversas matrizes de covariância, diferentemente do trabalho de Markowitz (1952). Desse trabalho surgiu o Capital Asset Pricing Model (CAPM), no qual se relacionam de maneira formal os retornos de uma ação com o retorno de mercado.

Além do problema de selecionar carteiras eficientes, outro problema era verificar se gestores de carteiras conseguiam prover retornos de maneira eficiente. Treynor e Mazuy (1966) analisam a capacidade dos gestores em realizar market timing, ou seja, verificam se os gestores conseguem capturar movimentos de mercado ao seu favor. Merton (1981) e Henriksson e Merton (1981) aprofundam o estudo de market timing separando a capacidade dos gestores de adicionar Alpha em movimentos de alta e de baixa do mercado. Henriksson (1984) avalia a capacidade dos gestores de fundos americanos capturarem movimentos de mercado ao seu favor, concluindo que essa capacidade é muito baixa.

Loomis (1966) foi o primeiro artigo publicado sobre Hedge Funds, intitulado de "The Jones Nobody Keeps Up With". Nesse artigo é descrito o modo de Alfred Winslow Jones gerenciar seu fundo: o Jones Hedge Fund. O fundo podia ter tanto posições compradas em ações, quanto vendidas. Nessa perspectiva, podemos dizer que esse foi o primeiro Hedge Fund conhecido na história. Esse fundo tinha o mesmo princípio dos fundos Long-Short atuais. Porém, com o mercado em crise na década de 70, muitos Hedge Funds foram liquidados e o interesse por esse tipo de veículo foi reduzido.

Apenas na metade da década de 90 é que se voltou a ter um interesse mais forte pelos Hedge Funds. Esse interesse dos investidores também atraiu o interesse da academia por esse assunto, principalmente com o objetivo de analisar se esse tipo de veículo é realmente uma fonte de retornos superiores. Schneeweis e Martin (2000) encontram evidências empíricas que portfólios nos Estados Unidos com Hedge Funds em sua composição apresentam um desempenho superior em termos de retorno esperado, volatilidade e índice de Sharpe, comparado a portifólios com apenas fundos tradicionais de renda fixa e ações. Outro artigo, como Liang (1998), 
encontra evidências que Hedge Funds conseguem prover retornos positivos, com volatilidade inferior aos índices de ações e com um correlação baixa com esses mesmos índices. De fato, os resultados de Fung e Hsieh (2002) indicam que os retornos de Hedge Funds não podem ser completamente explicados por fatores de mercado.

Estudando os fundos Long-Short, Jacobs e Levy (1999) examinam os vários aspectos de investir em fundos Long-Short como as estratégias que podem ser implementadas e os benefícios desse tipo de estratégia. Jacobs e Levy (1999) propõem um modelo para otimizar uma carteira com posições compradas e vendidas no mercado acionário, criando um portifólio neutro a movimentos de mercado. Patton (2004) propõe um teste estatístico para verificar se os fundos classificados como neutros ao mercado são realmente neutros, encontrando evidências de que mesmo os fundos considerados neutros possuem uma dependência positiva ao mercado. Já Capocci (2005) avaliou a exposição ao mercado de mais de 600 Hedge Funds classificados como Neutros na indústria global, chegando à conclusão de que os retornos da maioria dos fundos neutros não conseguem ser explicados pelos retornos de mercado.

Para o Brasil, Brito (2003) avalia o desempenho e a capacidade de market timing para fundos de gestão ativa, propondo um novo índice para avaliação desses fundos e, concluindo, que poucos gestores possuem tal capacidade. Penna (2007) testa a neutralidade dos fundos Long-Short no Brasil, encontrando que a maioria dos fundos possui dependência aos retornos de mercado. Leusin e Brito (2008) aplicam o modelo desenvolvido por Henriksson e Merton (1981) para avaliar o desempenho de diversos fundos de ações no Brasil, encontrando evidências que poucos gestores possuem tal capacidade. Castro e Minardi (2009) comparam o desempenho dos fundos de ações ativos e fundos passivos, concluindo que poucos fundos conseguiram prover os investidores com excesso de retorno.

O principal objetivo desse trabalho é analisar a exposição dos fundos LongShort no Brasil ao mercado acionário e avaliar se os mesmos são capazes de prover investidores com excesso de retorno. Nesse intuito, esse trabalho estuda como os retornos dos fundos são explicados pelos retornos de mercado através de regressões utilizando o Método Generalizado dos Momentos (GMM). Além disso, adicionamos um componente de market timing ao CAPM, avaliando se os gestores possuem habilidade de market timing e, em seguida, avaliamos a persistência dos gestores em relação ao excesso de retorno.

\section{Metodologia Empírica e Dados Utilizados}

\subsection{Estimando a exposição do fundo}

Para estimar o excesso de retorno dos fundos e seu grau de exposição ao mercado usamos o modelo CAPM:

$$
R_{i t}-R_{f t}=\alpha_{i}+\beta_{i}\left(R_{m t}-R_{f t}\right)+\epsilon_{i t}
$$


em que $R_{i t}$ é o retorno do fundo $i$ no período $t, R_{f t}$ é o retorno do ativo livre de risco no período $t$ e $R_{m t}$ é o retorno da carteira de mercado no período $t$. Nessa decomposição $\alpha_{i}$ captura, tanto o excesso de retorno gerado pela habilidade market timing do gestor, quanto sua capacidade de selecionar bons ativos (seletividade) e $\beta_{i}$ se refere à exposição ao mercado do fundo, quanto menor, em módulo, for seu Beta, menor será sua exposição ao mercado.

De fato, o modelo CAPM implica que $\alpha_{i}=0$, pois todo o retorno do ativo deveria ser explicado por meio do retorno de mercado. Em outras palavras, se supusermos que os gestores dos fundos têm acesso a toda informação pública relevante, testar se esta constante é nula é equivalente a testar a eficiência semiforte do mercado (Fama, 1970). Este raciocínio é interessante porque ele indica que o sucesso do fundo depende da habilidade do gestor em explorar ineficiências de mercado, criando arbitragens. Assim, quanto maior o $\alpha_{i}$, maior a habilidade do gestor. Neste sentido, é importante realizar o seguinte teste de hipótese: $H 0: \alpha_{i}=0$ versus $H 1: \alpha_{i}>0$.

Podemos também analisar se existem assimetrias na relação entre o fundo e o mercado, adicionando um novo termo à equação do CAPM, separando o que é capacidade de selecionar bons ativos (seletividade) e capacidade de market timing. Merton (1981) e Henriksson e Merton (1981) desenvolvem o modelo no qual a capacidade do gestor de market timing pode variar, dependendo das condições de mercado, conforme equação a seguir:

$$
R_{i t}-R_{f t}=\alpha_{i}+\beta_{i}\left(R_{m t}-R_{f t}\right)+\gamma_{i} \max \left[0, R_{f t}-R_{m t}\right]+\epsilon_{i t}
$$

O coeficiente $\gamma_{i}$ identificaria a habilidade de market timing do gestor e o coeficiente $\alpha_{i}$ identificaria a capacidade de seletividade do gestor. O sinal do coeficiente $\gamma_{i}$ determina se o gestor consegue acertar os movimentos de mercados. Se $\gamma_{i}$ é positivo, o gestor possui habilidade de market timing. Assim, se o market timing depende das condições de mercado, é possível estimar a exposição do fundo ao mercado quando o mercado esta em alta, quanto ele esta em baixa, sem causar viés na estimação de $\beta_{i}$. Note que, se $\left(R_{f t}-R_{m t}\right)>0$, o valor esperado do excesso de retorno do fundo é:

$$
E\left(R_{i t}-R_{m t}\right)=\alpha_{i}+\left(\beta_{i}-\gamma_{i}\right)\left(R_{m t}-R_{f t}\right)
$$

No entanto, se $\left(R_{f t}-R_{m t}\right)<0$, o valor esperado torna-se:

$$
E\left(R_{i t}-R_{m t}\right)=\alpha_{i}+\beta_{i}\left(R_{m t}-R_{f t}\right)
$$

As equações (1) e (2) são estimadas utilizando o GMM. Existe evidência empírica abundante que séries de retornos de ativos financeiros possuem correlação serial e heterocedasticidade. Com a utilização desse método, a distribuição de retornos pode ter tanto correlação serial como heterocedasticidade, pois a sua própria formulação já permite que seja modelada uma matriz robusta de variância 
e covariância. Para cada equação foram realizadas estimações utilizando como variáveis instrumentais apenas os regressores (o próprio retorno de mercado e a constante).

Com a equação (1), podemos testar a neutralidade dos fundos por meio da hipótese nula $H 0: \beta_{i}=0$. Como hipótese alternativa, temos que o fundo não é neutro em relação à carteira de mercado, ou seja, $H 1: \beta_{i} \neq 0$. Assim, se não podemos rejeitar a hipótese nula, podemos dizer que movimentos de mercados não conseguem explicar os retornos do fundo e, por conseguinte, o fundo possui neutralidade em relação a carteira de mercado. Já, se conseguimos rejeitar a hipótese nula, podemos dizer que os movimentos de mercado afetam o fundo, logo o fundo não é neutro em relação ao mercado.

Entretanto, a equação (1) pode omitir um termo relevante, uma vez que os fundos podem ter comportamentos diferentes, dependendo do mercado. Neste caso o termo omitido seria $\max \left[0, R_{f t}-R_{m t}\right]$ que, inclusive, possui correlação negativa com o regressor $R_{m t}-R_{f t}$. Portanto, a omissão desta variável causaria viés. Para corrigir esse possível viés, pode-se utilizar a equação (2), no qual o parâmetro $\gamma_{i}$ mensura a capacidade de market timing do gestor. Para testar se o gestor consegue capturar movimentos de alta do mercado a seu favor e proteger sua carteira quando o mercado cai realizamos o seguinte teste de hipótese: $H 0: \gamma_{i}=0$ versus $H 1: \gamma_{i}>0$. Portanto, no caso da assimetria ser positiva, o gestor possui habilidade de market timing positiva. Se o fundo tem uma assimetria negativa, então ele possui uma habilidade de market timing negativa. Consequentemente, quando o mercado cai, ele cai tanto quanto o mercado ou mais e quando o mercado sobe, o gestor não consegue capturar integralmente a alta.

\subsection{Dados}

A base de dados utilizada foi construída por meio de dados públicos, divulgados pela ANBID (Associação Nacional dos Bancos de Investimento) e CVM (Comissão de Valores Mobiliários). Porém, foi utilizado o Sistema Quantum Axis - versão 5.3.2, para facilitar o acesso e a consolidação de todos os dados. O período utilizado para levantamento dos dados foi de 02 de janeiro de 2001 até 31 de março de 2008.

Os fundos que utilizam estratégia Long-Short no Brasil podem ser classificados de diferentes formas. Por exemplo, um gestor de fundo Long-Short pode classificar seu fundo como Multimercado, Long-Short e Ações para a ANBID. ${ }^{2}$ Assim, não existe uma maneira muito simples e uniforme para selecionar os fundos. Para a seleção dos fundos utilizados nesse trabalho, primeiramente foram considerados todos os fundos classificados na base de dados ANBID como Multimercados, Long-Short e Ações. Depois foram excluídos fundos classificados como exclusivos. Em seguida foram excluídos fundos que não cobravam taxas de administração e/ou performance bem como fundos que apenas replicavam in-

\footnotetext{
${ }^{2}$ A classificação dos fundos pela instituição pode ter sido alterada depois que a base de dados desse artigo foi constituída.
} 
teiramente a estratégia de um fundo já aberto, fundos comumente conhecidos na industria como fundos "espelho". Também foram retirados os fundos que não cobravam nenhuma taxa, pois gostaríamos de ter uma base uniforme de comparação. Para finalizar, avaliamos no sítio da $\mathrm{CVM}^{3}$ se os fundos possuem apenas na sua composição de fechamento do ano de 2007 posições compradas e vendidas no mercado acionário, assim como seus derivativos. Fundos que possuem outros ativos além de ações e derivativos em sua alocação foram retirados da amostra. Dessa maneira, foram selecionados 76 fundos. Para a análise com dados diários, foram retirados da amostra fundos que tinham menos de 6 meses de histórico de cotas. Para a análise com dados mensais, foram retiradas da amostra fundos com menos de 24 meses de histórico de cotas. Não foi realizado nenhum filtro em relação ao tamanho (patrimônio) dos fundos. A figura 3 mostra o crescimento do número de fundos, na amostra utilizada, ao longo do tempo.

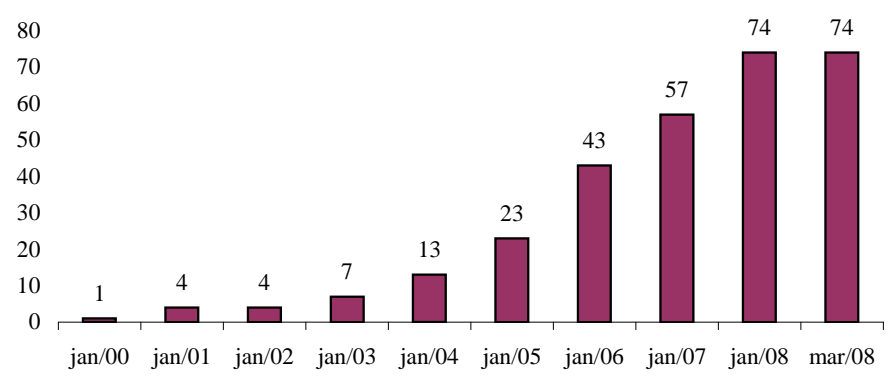

Figura 3

Evolução do número de fundos abertos na amostra

O ativo livre de risco selecionado foi o CDI (Certificado de Depósito Interbancário). Apesar da controvérsia no mercado brasileiro quanto a qual ativo livre de risco utilizar (CDI, SELIC ou poupança), o CDI foi escolhido, pois apresenta algumas características mais adequadas para esse tipo de estudo. Em especial, o custo de oportunidade da maioria dos investidores em Multimercados no Brasil é o CDI, pois esses investidores possuem acesso a investimentos com essa taxa de retorno. Como índice representativo da carteira de mercado foi utilizado o Índice Bovespa Médio (Ibovespa Médio). Apesar de nenhum índice refletir integralmente a carteira de mercado, a vantagem é que este é mais conhecido e popular, além de ser o índice de referência do mercado. Como Campbell et alii (1997) apontam, se a proxy da carteira de mercado utilizada possui uma correlação superior a 0,70 com a verdadeira carteira de mercado, então a rejeição do CAPM com esta proxy, indica que o modelo CAPM com a verdadeira carteira de mercado também seria rejeitado. Assim, enquanto houver uma correlação alta entre as proxies utilizadas e a verdadeira carteira de mercado, a análise do modelo ainda é válida.

\footnotetext{
${ }^{3}$ Ver http://www.cvm.gov.br/.
} 
O retorno dos fundos, bem como dos índices, foi calculado através de retorno composto continuamente com base na cota ou valor de fechamento de cada um dos fundos ou índice respectivamente, assim:

$$
R_{i t}=\ln \left(P_{i t} / p_{i t-1}\right)
$$

em que $P_{i t}$ é o valor da cota do fundo $i$ ou do índice, no período $t$.

Por fim, um dos principais problemas enfrentados por pesquisadores dessa área é o chamado Suvivorship Bias, ou viés de sobrevivência (Brown et alii, 2001, Carhart et alii, 2002). Muitas bases de dados retiram de seus bancos de dados fundos que foram incorporados ou que fecharam, fazendo com que apenas fundos que ainda existam sejam analisados. No caso desse trabalho, foram mantidos os fundos que fecharam ou os que foram incorporados por outros fundos. Assim, não existe viés de sobrevivência na amostra utilizada para esse estudo. Contudo, para as análises realizadas em janelas menores de tempo, ou em análises com dados mensais, alguns fundos podem ter sido retirados da amostra para garantir um número mínimo de observações ao longo do tempo. Por exemplo, na seção 4.2 analisamos a performance dos fundos usando dados em freqüência mensal e, neste caso, excluímos os fundos com menos de 2 anos de informação (24 observações).

\subsection{Avaliação do período analisado}

O período levantando para estudo foi um período volátil para o mercado acionário, aqui ilustrado pelo Ibovespa. Contudo, apesar da volatilidade, o Ibovespa apresentou retornos positivos em todos os anos, com exceção do início do ano de 2008. Para avaliar como os fundos Long Short se comportaram nesse período, avaliamos o Índice de fundos Long-Short ${ }^{4}$ da consultoria Risk-Office (ILS). A figura 4 ilustra a comparação entre o Ibovespa , o CDI e o ILS para o período de janeiro de 2003 até março de 2008. O estudo é importante nesse período para averiguar se os retornos dos fundos Long-Short foram apenas gerados por retornos de mercado ou se houve geração de excesso de retorno para os investidores. Não faria sentido aos investidores alocar um percentual de seus recursos nesse tipo de fundo para apenas conseguirem capturar retornos de mercados.

\footnotetext{
${ }^{4}$ Índice disponível no site www.riskoffice.com.br, bem como sua composição e metodologia 


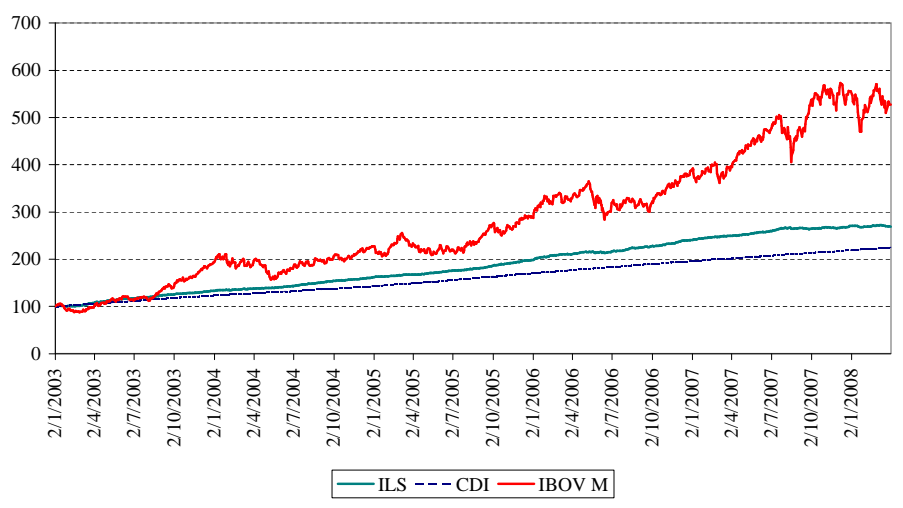

Figura 4

Evolução do mercado

\subsection{Bancos múltiplos e gestores independentes}

Os fundos Long-Short no Brasil são geridos basicamente por dois tipos de instituições. A primeira são os Bancos Múltiplos (BM), bancos que possuem além da atividade de gestão de investimentos, atividades como operações de crédito, operações de atacado, etc. Além dos bancos, temos os Gestores Independentes (GI) que geralmente são empresas pequenas focadas na atividade de gestão de investimentos. Teoricamente, dado o grau de especialização dos Gestores Independentes, seus fundos deveriam ter um melhor desempenho que os fundos dos Bancos Múltiplos. Na amostra desse estudo, dos 76 fundos selecionados, 14 fundos são geridos por Bancos Múltiplos. O restante é gerido por bancos de investimentos ou empresas de gestão independentes.

\subsection{Apreçamento dos fundos long-short}

Um ponto importante que deve ser levantado é sobre como a marcação a mercado dos fundos Long-Short é realizada no Brasil. Até o último dia útil de abril de 2008, o apreçamento das ações que faziam parte do fundo era feito através do preço médio da ação do dia. Já posições em contratos futuro eram precificadas com o preço de fechamento do dia. Assim, caso um fundo tivesse uma posição comprado em uma carteira de ações (apreçadas pelo preço médio) e outra posição vendida em contrato futuro de Índice Ibovespa (apreçado pelo preço de fechamento), o fundo teria uma distorção de preços dada à diferença na maneira de apreçar diferentes ativos. Para exemplificar este problema, comparamos os dados diários do Índice Ibovespa Médio, índice que reflete o preço médio das ações com o Índice Ibovespa, índice que reflete o preço de fechamento das ações. Apesar de possuírem a mesma composição, a correlação entre estes dois índices é de apenas $71 \%$ para dados diários do período de janeiro de 2001 até março de 2008. A mesma análise foi realizada para dados mensais, a correlação entre o Índice 
Ibovespa e o Índice Ibovespa Médio para o mesmo período foi de 99A partir de inicio de maio de 2008, uma nova regulamentação publicada pela CVM (Comitê de Valores Monetários) definiu que as ações que fazem parte de fundos de investimento, deveriam ser precificadas pelo preço de fechamento, assim como é feito para o caso de contratos futuro. Isso deve diminuir as distorções que acontecem quando os fundos Long-Short são apreçados.

\section{Resultados Empíricos}

Nessa seção apresentamos os resultados encontrados. As seções 4.1 e 4.2 apresentam os resultados para dados diários e mensais, respectivamente. Para ambas as partes foram consideradas estimações com e sem a inclusão do componente de market timing $(\gamma)$, conforme equações (1) e (2), respectivamente. Os resultados completos de todas as regressões são apresentados no Anexo I. A seção 4.3 faz uma análise da persistência do excesso de retorno $(\alpha)$ obtido via CAPM, pois ao investidor, interessa finalmente, a soma das habilidades de market timing e seletividade.

\subsection{Dados diários}

A Tabela 1 mostra o resumo dos resultados obtidos com as regressões utilizando dados diários desde o início do fundo. Percebe-se que a média do excesso de retorno gerado pelos gestores é positivo, porém, apenas $25 \%$ da amostra possui valores significativamente positivos quando estimamos o modelo CAPM tradicional. Contudo, quando separamos o excesso de retorno em dois componentes (seletividade e market timing), percebemos que o número de fundos com seletividade significativamente positiva dobra, aproximadamente. Em contrapartida, também percebemos que a média do componente de market timing é negativo e, de fato, nenhum fundo apresenta $\gamma$ significativamente positivo. Assim, na média, existem gestores que possuem capacidade de selecionar bons ativos, entretanto a indústria de fundos, na média, não consegue capturar movimentos de mercado de forma eficiente. Quando avaliamos a média da exposição dos mesmos ao mercado, ela é positiva em ambos os casos, contudo quando separamos o parâmetro Alpha, do modelo CAPM tradicional, em um componente de seletividade e outro de market timing, conforme equação (2), a exposição média ao mercado é menor.

Considerando apenas valores significativamente positivos, 19 fundos pela estimação pelo modelo CAPM obtiveram Alpha positivo. Os dois fundos que conseguiram obter maior Alpha foram o Unibanco Equity Hedge e o Pólo Ações, com $34,67 \%$ e $22,05 \%$, ao ano, respectivamente. A maioria dos fundos teve exposição ao mercado positiva. Os maiores Betas foram do Mandarim Long Short $(33,82 \%)$ e do Tarpon Long Short (27,58\%).

Quando adicionamos o componente de assimetria, 43 fundos tiveram Alpha significativamente positivos. Os dois fundos que conseguiram obter maior Alpha foram o HG Strategy Long Short e o Fama Shooter, com alpha de 40,17\% e 37,03\% ao ano, respectivamente. Em contrapartida, apenas 3 fundos tiveram capacidade 
de market timing, ou seja, Gama positivo e nenhum fundo conseguiu obter Alpha e Gama positivos significante simultaneamente. Em relação à exposição ao mercado, os dois fundos que tiveram maior Beta foram Mandarim Long Short, com $30,80 \%$, e o Tarpon Long Short, com 24,96\%.

Tabela 1

Resultado da estimação

\begin{tabular}{|c|c|c|c|}
\hline \multicolumn{4}{|c|}{$\begin{array}{l}\text { Número de fundos: } 76 \\
\text { Retornos: desde o início do fundo - dados diários }\end{array}$} \\
\hline & \multirow{2}{*}{$\begin{array}{c}\text { CAPM } \\
\text { Alpha }(\alpha)^{*} \\
\end{array}$} & \multicolumn{2}{|c|}{ CAPM + Assimetria } \\
\hline & & Alpha $(\alpha)^{*}$ & $\operatorname{Gama}(\gamma)$ \\
\hline Média & $1,38 \%$ & $9,96 \%$ & $-5,26 \%$ \\
\hline$\%$ Positivos & $60,53 \%$ & $89,47 \%$ & $10,53 \%$ \\
\hline$\%$ Negativos & $39,47 \%$ & $10,53 \%$ & $89,47 \%$ \\
\hline Teste de Hipótese (5\% Unicaudal): & \multicolumn{3}{|c|}{ H0: $\alpha(\gamma)=0$ HA: $\alpha(\gamma)>0$} \\
\hline$\%$ Significativos & $25,00 \%$ & $56,58 \%$ & $0,00 \%$ \\
\hline \multirow[t]{3}{*}{ Media } & $9,16 \%$ & $14,39 \%$ & - \\
\hline & CAPM & \multicolumn{2}{|c|}{ CAPM + Assimetria } \\
\hline & $\operatorname{Beta}(\beta)$ & \multicolumn{2}{|c|}{$\operatorname{Beta}(\beta)$} \\
\hline Média & $0,04 \%$ & \multicolumn{2}{|l|}{0,01} \\
\hline$\%$ Positivos & $84,21 \%$ & \multicolumn{2}{|l|}{$55,26 \%$} \\
\hline$\%$ Negativos & $15,79 \%$ & \multicolumn{2}{|l|}{$44,74 \%$} \\
\hline Teste de Hipótese (5\% Bicaudal): & \multicolumn{3}{|c|}{$\mathrm{H} 0: \beta=0$ HA: $\beta \neq 0$} \\
\hline$\%$ Significativos & $60,53 \%$ & \multicolumn{2}{|l|}{$35,53 \%$} \\
\hline Media** & $0 ., 06$ & \multicolumn{2}{|l|}{0,03} \\
\hline \% Positivo & $93,48 \%$ & \multicolumn{2}{|l|}{$62,96 \%$} \\
\hline$\%$ Negativo & $6,52 \%$ & \multicolumn{2}{|l|}{$37,04 \%$} \\
\hline
\end{tabular}

Na Tabela 2 e na Tabela 3 são reportados os resultados utilizando a mesma janela de tempo para avaliar os fundos. Dessa forma é possível avaliar os gestores sob as mesmas condições de mercado. No caso da Tabela 2 os dados se referem ao período de abril de 2007 até março de 2008, ou seja, 12 meses de avaliação. Já no caso da Tabela 3, os dados se referem ao período de abril de 2006 até março de 2008, ou seja, 24 meses. Dessa forma é possível avaliar uma janela mais curta de tempo e outra mais longa. Em ambos os casos só foram inseridos na amostra fundos que possuíam histórico de cotas completo para os períodos analisados. 
Tabela 2

Resultado da estimação

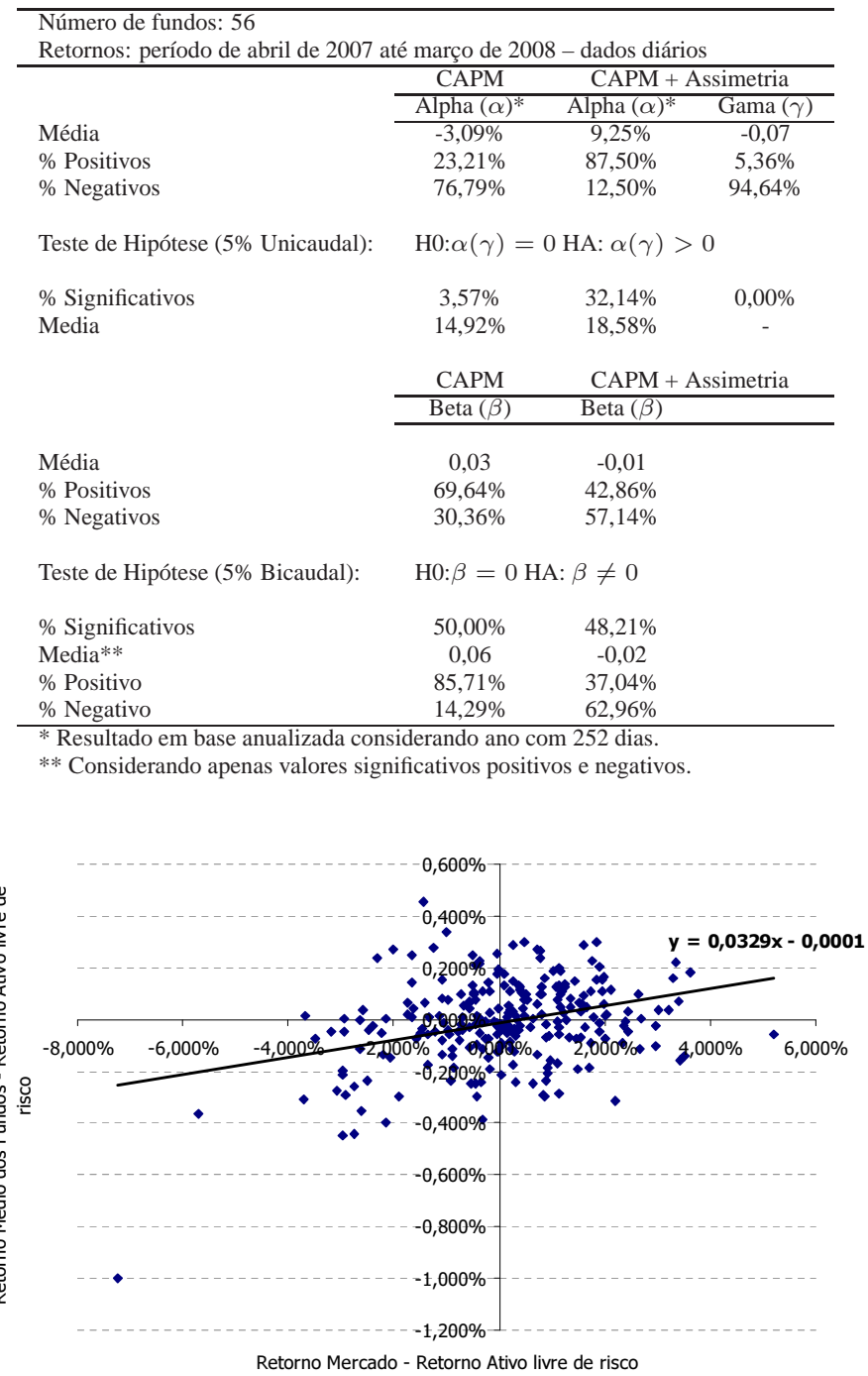

Figura 5

Média dos fundos vs. mercado

A média do excesso de retorno dos fundos $(\alpha)$ foi negativa tanto no período de março de 2007 até março de 2008 quanto no período de abril de 2006 até março de 2008. Nos dois casos, o número de fundos com excesso de retorno significativamente positivo é bastante reduzido, apenas dois fundos em cada uma das amostras, 
sendo o Orbe Balance Multimercado e Pólo Latitude 84 no primeiro caso e o BRZ Long Short e Credit Suisse Long Short no segundo. Quando inserimos o componente de market timing, para ambas as janelas de análise a seletividade $(\alpha)$ é positiva e o market timing $(\gamma)$ é negativo. Na primeira amostra 18 fundo tem seletividade significativamente maior do que zero e nenhum fundo possui market timing significativamente maior do que zero. Na segunda amostra esses números são 21 fundos para seletividade e novamente nenhum fundo para market timing. Quando avaliamos a exposição ao mercado dos fundos, o Beta $(\beta)$, a média da exposição ao mercado é positiva, na estimação utilizando o CAPM Tradicional nas duas janelas de dados, porém próxima a zero. No entanto, rejeitamos que 28 (50\%) fundos possuam Beta nulo de abril de 2007 a março de 2008, e esse número se torna 27 (42\%) na janela de abril de 2006 a março de 2008. Quando adicionamos o componente de market timing $(\gamma)$ para o mesmo período, a exposição é negativa na primeira janela e positiva na segunda janela, porém próxima de zero. Nas duas janelas rejeitamos em aproximadamente $50 \%$ dos casos que a exposição seja nula, mas mesmo nesses casos o Beta médio é pequeno. Assim, retornos de mercado pouco explicam os retornos dos fundos.

A figura 4 relaciona a média dos retornos dos fundos na amostra, descontado do retorno do ativo livre de risco, com o risco de mercado, também descontado do retorno do ativo livre de risco, do período de março de 2007 até março de 2008. Percebe-se que a média da indústria tem uma baixa exposição ao risco de mercado. A figura 5 ilustra essa mesma exposição, porém utilizando o período de abril de 2006 até março de 2008. 
Tabela 3

Resultado da estimação

\begin{tabular}{|c|c|c|c|}
\hline \multicolumn{4}{|c|}{$\begin{array}{l}\text { Número de fundos: } 42 \\
\text { Retornos: período de abril de } 2006 \text { até março de } 2008 \text { - dados diários }\end{array}$} \\
\hline & \multirow{2}{*}{ CAPM } & \multicolumn{2}{|c|}{ CAPM + Assimetria } \\
\hline & & Alpha $(\alpha)^{*}$ & $\operatorname{Gama}(\gamma)$ \\
\hline Média & $-0,71 \%$ & $9,54 \%$ & $-0,07$ \\
\hline$\%$ Positivos & $35,71 \%$ & $100,00 \%$ & $2,38 \%$ \\
\hline$\%$ Negativos & $64,29 \%$ & $0,00 \%$ & $97,62 \%$ \\
\hline Teste de Hipótese (5\% Unicaudal): & \multicolumn{3}{|c|}{ H0: $\alpha(\gamma)=0$ HA: $\alpha(\gamma)>0$} \\
\hline$\%$ Significativos & $4,76 \%$ & $50,00 \%$ & $0,00 \%$ \\
\hline \multirow[t]{3}{*}{ Media } & $3,90 \%$ & $15,16 \%$ & - \\
\hline & CAPM & \multicolumn{2}{|c|}{ CAPM + Assimetria } \\
\hline & $\operatorname{Beta}(\beta)$ & \multicolumn{2}{|c|}{$\operatorname{Beta}(\beta)$} \\
\hline Média & 0,05 & \multicolumn{2}{|l|}{0,01} \\
\hline$\%$ Positivos & $85,71 \%$ & \multicolumn{2}{|l|}{$50,00 \%$} \\
\hline$\%$ Negativos & $14,29 \%$ & \multicolumn{2}{|l|}{$50,00 \%$} \\
\hline Teste de Hipótese (5\% Bicaudal): & \multicolumn{3}{|c|}{$\mathrm{H} 0: \beta=0 \mathrm{HA}: \beta \neq 0$} \\
\hline$\%$ Significativos & $64,29 \%$ & \multicolumn{2}{|l|}{$47,62 \%$} \\
\hline Media** & 0,07 & \multicolumn{2}{|l|}{0,03} \\
\hline$\%$ Positivo & $96,30 \%$ & \multicolumn{2}{|l|}{$60,00 \%$} \\
\hline$\%$ Negativo & $3,70 \%$ & \multicolumn{2}{|l|}{$40,00 \%$} \\
\hline
\end{tabular}

Um ponto interessante quando avaliamos o período de janeiro de 2006 até dezembro de 2007, é que apesar do excesso de retorno ser positivo em todos os fundos com valores significantes, o componente de market timing $(\gamma)$, é negativo em quase todos fundos. Os gestores conseguem rentabilizar suas carteiras através de uma boa seleção de ativos, uma vez que o excesso de retorno é positivo, porém não conseguem rentabilizar suas carteiras através da captura de movimentos de mercado, uma vez que o componente de market timing é negativo, conforme ilustrado nas equações (1) e (2). 


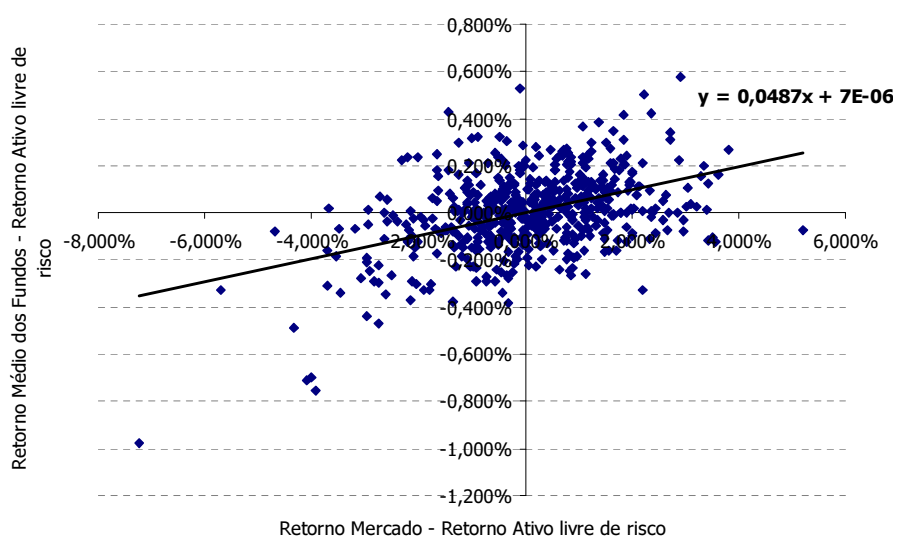

Figura 6

Média dos fundos vs. mercado

\subsection{Dados mensais}

Para os dados mensais só foram utilizados fundos com mais de 2 anos de histórico de cotas para que a análise fosse realizada com no mínimo 24 observações. Assim, houve uma redução da amostra de fundos utilizados para 45 fundos. Apesar da utilização de dados mensais, o número de valores significantes permaneceu baixo, tanto para a análise com o componente de market timing, quanto sem. Isso pode ocorrer se realmente não existam muitos fundos que consigam prover excesso de retorno aos investidores e, assim, não rejeitamos a hipótese nula de que os valores sejam zero.

A Tabela 4 resume os resultados encontrados com a regressão dos dados mensais. Para a maioria das estimações a média do excesso de retorno foi positiva; porém, apenas em 8 fundos encontramos excesso de retorno significativamente maior do que zero. A média da exposição ao mercado é positiva, porém próxima a zero e em 20 fundos rejeitamos que tal exposição seja nula. Separando os componentes de seletividade e market timing, observamos que o primeiro é em média positivo e o segundo negativo. Encontramos evidência de seletividade significativamente positiva para $17(37,78 \%)$ fundos e para o market timing esse número é apenas $2(4,44 \%)$. A exposição média é positiva, porém próxima de zero. De fato, só $6(13,33 \%)$ dos fundos apresentaram Betas significativos. Finalmente, assim como na análise com dados diários, a média do excesso de retorno foi positiva e a média do componente de market timing foi negativa.

A Tabela 5 utiliza a mesma amostra de fundos para a análise de dados mensais, porém com dados diários. Dessa forma é possível avaliar a diferença entre as estimações com dados mensais e com dados diários. Qualitativamente, temos as mesmas conclusões: a exposição dos fundos ao mercado é positiva, bem como o excesso de retorno. Já a capacidade de market timing é negativa. 
Tabela 4

Resultado da estimação

\begin{tabular}{|c|c|c|c|}
\hline \multicolumn{4}{|c|}{$\begin{array}{l}\text { Número de fundos: } 45 \\
\text { Retornos: desde o início do fundo - dados mensais }\end{array}$} \\
\hline \multirow[t]{3}{*}{ 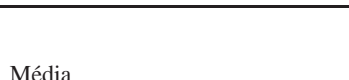 } & \multirow{3}{*}{$\begin{array}{c}\text { CAPM } \\
\text { Alpha }(\alpha)^{*} \\
\end{array}$} & \multicolumn{2}{|c|}{ CAPM + Assimetria } \\
\hline & & Alpha $(\alpha)^{*}$ & $\operatorname{Gama}(\gamma)$ \\
\hline & & $3,65 \%$ & $-0,06$ \\
\hline$\%$ Positivos & $71,11 \%$ & $80,00 \%$ & $24,44 \%$ \\
\hline$\%$ Negativos & $28,89 \%$ & $20,00 \%$ & $75,56 \%$ \\
\hline Teste de Hipótese (5\% Unicaudal): & \multicolumn{3}{|c|}{ H0: $\alpha(\gamma)=0$ HA: $\alpha(\gamma)>0$} \\
\hline$\%$ Significativos & $17,78 \%$ & $37,78 \%$ & $4,44 \%$ \\
\hline \multirow[t]{3}{*}{ Media } & $7,90 \%$ & $7,79 \%$ & $71,82 \%$ \\
\hline & CAPM & \multicolumn{2}{|c|}{ CAPM + Assimetria } \\
\hline & $\operatorname{Beta}(\beta)$ & \multicolumn{2}{|c|}{$\operatorname{Beta}(\beta)$} \\
\hline Média & 0,07 & \multirow{3}{*}{\multicolumn{2}{|c|}{$\begin{array}{c}0,05 \\
68,89 \% \\
31,11 \%\end{array}$}} \\
\hline \% Positivos & $88,89 \%$ & & \\
\hline$\%$ Negativos & $11,11 \%$ & & \\
\hline Teste de Hipótese (5\% Bicaudal): & \multicolumn{3}{|c|}{$\mathrm{H} 0: \beta=0 \mathrm{HA}: \beta \neq 0$} \\
\hline$\%$ Significativos & $44,44 \%$ & \multicolumn{2}{|l|}{$13,33 \%$} \\
\hline Media** & 0,10 & \multicolumn{2}{|l|}{0,23} \\
\hline$\%$ Positivo & $100,00 \%$ & \multicolumn{2}{|l|}{$100,00 \%$} \\
\hline$\%$ Negativo & $0,00 \%$ & \multicolumn{2}{|l|}{$0,00 \%$} \\
\hline
\end{tabular}

Tabela 5

Resultado da estimação

\begin{tabular}{|c|c|c|c|}
\hline \multicolumn{4}{|c|}{$\begin{array}{l}\text { Número de fundos: } 45 \\
\text { Retornos: desde o início do fundo - dados diários }\end{array}$} \\
\hline & \multirow{2}{*}{$\frac{\text { CAPM }}{\text { Alpha }(\alpha)^{*}}$} & \multicolumn{2}{|c|}{ CAPM + Assimetria } \\
\hline & & Alpha $(\alpha)^{*}$ & Gama $(\gamma)$ \\
\hline Média & $2,40 \%$ & $10,41 \%$ & $-0,05$ \\
\hline$\%$ Positivos & $80,00 \%$ & $95,56 \%$ & $6,67 \%$ \\
\hline$\%$ Negativos & $20,00 \%$ & $4,44 \%$ & $93,33 \%$ \\
\hline Teste de Hipótese (5\% Unicaudal): & \multicolumn{3}{|c|}{$\mathrm{H} 0: \alpha(\gamma)=0 \mathrm{HA}: \alpha(\gamma)>0$} \\
\hline$\%$ Significativos & $31,11 \%$ & $73,33 \%$ & $6,67 \%$ \\
\hline \multirow[t]{3}{*}{ Media } & $6,36 \%$ & $12,97 \%$ & $2,23 \%$ \\
\hline & CAPM & \multicolumn{2}{|c|}{ CAPM + Assimetria } \\
\hline & $\operatorname{Beta}(\beta)$ & \multicolumn{2}{|c|}{$\operatorname{Beta}(\beta)$} \\
\hline Média & $3,88 \%$ & \multicolumn{2}{|l|}{$1,20 \%$} \\
\hline$\%$ Positivos & $84,44 \%$ & \multicolumn{2}{|l|}{$57,78 \%$} \\
\hline$\%$ Negativos & $15,56 \%$ & \multicolumn{2}{|l|}{$42,22 \%$} \\
\hline Teste de Hipótese (5\% Bicaudal): & \multicolumn{3}{|c|}{$\mathrm{H} 0: \beta=0 \mathrm{HA}: \beta \neq 0$} \\
\hline$\%$ Significativos & $73,33 \%$ & \multicolumn{2}{|l|}{$44,44 \%$} \\
\hline Media** & 0,05 & \multicolumn{2}{|l|}{0,03} \\
\hline$\%$ Positivo & $90,91 \%$ & \multicolumn{2}{|l|}{$60,00 \%$} \\
\hline$\%$ Negativo & $9,09 \%$ & \multicolumn{2}{|l|}{$40,00 \%$} \\
\hline
\end{tabular}




\subsection{Gestores independentes vs. bancos múltiplos}

Comparando o desempenho dos fundos geridos por Gestores Independentes (GI) com os fundos que são geridos por Bancos Múltiplos (BM), percebemos que em quase todas as janelas de tempo utilizadas na análise pelo modelo CAPM, os fundos geridos por Gestores Independentes, na média, não conseguem gerar um excesso de retorno superior aos fundos geridos por Bancos Múltiplos. A média dos excessos de retornos das duas categorias são bem próximas. Quando adicionamos o componente de assimetria, em todas as janelas de análise os fundos geridos por Gestores Independentes, na média, conseguem prover investidores com seletividade superior aos fundos de Bancos Múltiplos. Quando avaliamos a dependência dos retornos dos fundos em relação aos retornos de mercado, percebemos que a média da exposição dos fundos geridos por Gestores Independentes é maior do que os fundos geridos por Bancos Múltiplos. Em relação à capacidade de market timing, independente do tipo de instituição, na média a capacidade é negativa. A Tabela 6 fornece um resumo dos resultados encontrados.

Tabela 6

Comparação - gestores independentes vs. bancos múltiplos

\begin{tabular}{|c|c|c|c|c|c|}
\hline \multirow{3}{*}{ Periodo } & \multicolumn{5}{|c|}{ Média } \\
\hline & CAPM & \multicolumn{3}{|c|}{ CAPM + Assimetria } & \multirow[b]{2}{*}{$\operatorname{Gama}(\gamma)$} \\
\hline & Alpha $(\alpha)^{*}$ & $\operatorname{Beta}(\beta)$ & Alpha $(\alpha)^{*}$ & Beta $(\beta)$ & \\
\hline \multicolumn{6}{|c|}{ Desde do início do fundo - dados diários } \\
\hline GI (61 fundos) & $1,16 \%$ & $4,47 \%$ & $10,96 \%$ & $1,32 \%$ & $-5,94$ \\
\hline BM (15 Fundos) & $2,25 \%$ & $2,34 \%$ & $5,89 \%$ & $1,02 \%$ & $-2,50 \%$ \\
\hline \multicolumn{6}{|c|}{ Periodo de março 2007 até março 2008 - dados diários } \\
\hline GI (47 fundos) & $-3,27 \%$ & $3,94 \%$ & $10,12 \%$ & $-0,35 \%$ & $-8,02 \%$ \\
\hline BM (9 Fundos) & $-2,13 \%$ & $-0,10 \%$ & $4,72 \%$ & $-2,36 \%$ & $4,23 \%$ \\
\hline \multicolumn{6}{|c|}{ Anos de 2006 e 2007 - dados diários } \\
\hline GI (34 fundos) & $0,42 \%$ & $5,60 \%$ & $10,60 \%$ & $2,16 \%$ & $-6,51$ \\
\hline BM (8 Fundos) & $-0,53 \%$ & $1,75 \%$ & $6,05 \%$ & $-0,56 \%$ & $-4,37 \%$ \\
\hline \multicolumn{6}{|c|}{ Desde do início do fundo - dados diários } \\
\hline GI (37 fundos) & $2,08 \%$ & $8,34 \%$ & $3,74 \%$ & $6,26 \%$ & $-5,43$ \\
\hline BM (8 Fundos) & $0,64 \%$ & $0,44 \%$ & $3,20 \%$ & $-3,28 \%$ & $-9,40 \%$ \\
\hline
\end{tabular}

\subsection{Análise de persistência}

É importante analisar a persistência do excesso de retorno dos fundos, pois fundos com excesso de retorno positivos e persistentes são bastante atrativos. Esta análise pode, em princípio, ser feita usando o modelo CAPM ou o modelo com assimetria de Henriksson e Merton. No entanto, ao investidor, interessa a soma das habilidades de market timing e seletividade, ou seja, quanto excesso de retorno o gestor de um fundo é capaz de produzir, independente da composição das habilidades. Por essa razão optamos por fazer a análise de persistência usando o modelo CAPM. É importante mencionar também que existem algumas críticas na literatura ao modelo de Henriksson e Merton, destacando-se a possibilidade de ocorrer uma correlação negativa artificial entre as medidas de seletividade e market 
timing. ${ }^{5}$ De fato, os resultados anteriores são coerentes com essa possibilidade.

A Tabela 7 apresenta os Alphas de 42 fundos obtidos em 5 períodos. O período completo de abril de 2006 a março de 2008, e os sub-períodos 1, 2, 3 e 4 referentes ao $1^{\circ}, 2^{\circ}, 3^{\circ}$ e $4^{\circ}$ semestres dessa janela de dois anos. O período é interessante, pois constitui um período de alta e de baixa para o mercado, assim é interessante verificar quais foram os fundos que conseguiram apresentar persistência tanto no mercado de alta, quanto de baixa. Avaliando os fundos, apenas dois fundos foram capazes de prover excesso de retorno (Alpha) positivo e significativo no período de abril de 2006 a março de 2008 (Período C), que foram os fundos BRZ Long Short e Credit Suisse Long Short, contudo os mesmos só conseguiram prover excesso de retornos positivos em apenas dois sub-períodos, os dois primeiros, dos quatro avaliados.

O período no qual um maior número de fundos conseguiu prover Alpha aos investidores foi o Período 2, que corresponde ao período de setembro de 2006 até março de 2007, quando 13 fundos apresentaram excesso de retorno positivo e significativo. Em contrapartida, nenhum fundo foi capaz de prover Alpha no Período 3 e apenas 1 no Período 4. De fato, no Período 4, que corresponde a janela de setembro de 2007 a março de 2008, 12 fundos apresentaram Alpha negativo e significativo.

Comparando o comportamento dos fundos e sua respectiva geração de Alpha nos sub-periodos, nenhum fundo foi capaz de gerar excesso de retorno em mais de dois sub-periodos. Assim, como a persistência seria a capacidade do gestor de gerar excesso de retorno em diversos períodos consecutivos, concluímos que, no período analisado, os gestores não provem os investidores com persistência de Alpha.

\footnotetext{
${ }^{5}$ Para maiores detalhes ver Jiang (2003) e Cuthbertson et alii (2006). 
Tabela 7

Avaliacao de persistencia do excesso de retorno (alpha) - modelo CAPM

\begin{tabular}{|c|c|c|c|c|c|}
\hline \multirow[b]{3}{*}{ Fundo } & \multirow{2}{*}{\multicolumn{5}{|c|}{ Retornos: Abril de 2006 até Março de 2008 - Dados Diários }} \\
\hline & & & & & \\
\hline & Periodo C & Periodo 1 & Periodo 2 & Periodo 3 & Periodo 4 \\
\hline ABN AMRO STAR LONG SHORT FIC MULTIMERCADO & $-0,76 \%$ & $-1,63 \%$ & $2,94 \%$ & $-4,46 \%$ & $-0,48 \%$ \\
\hline ÁTICO LONG SHORT FI MULTIMERCADO & $-0,59 \%$ & $1,76 \%$ & $-0,17 \%$ & $-1,45 \%$ & $-5,25 \%$ \\
\hline BANIF NITOR FI MULTIMERCADO & $-0,49 \%$ & $2,94 \% *$ & $1,50 \%$ & $-0,89 \%$ & $-4,41 \%$ \\
\hline $\begin{array}{l}\text { BBM LONG SHORT FI MULTIMERCADO } \\
\text { BBU }\end{array}$ & $-1,86 \%$ & $5,86 \% *$ & $6,39 \% *$ & $-3,61 \%$ & $-15,24 \%$ \\
\hline BNY MELLON ARX LONG AND SHORT FI MULTIMERCADO & $2,46 \%$ & $10,16 \% *$ & $4,04 \%$ & $-1,59 \%$ & $-2,91 \%$ \\
\hline BRADESCO LONG SHORT FI MULTIMERCADO & $0,30 \%$ & $-2,09 \%$ & $1,71 \%$ & $-2,36 \%$ & $4,40 \%$ \\
\hline $\begin{array}{l}\text { BRZ LONG SHORT FI MULTIMERCADO } \\
\text { BDD }\end{array}$ & $1,59 \% *$ & $3,25 \% *$ & $3,07 \% *$ & $0,72 \%$ & $-0,47 \%$ \\
\hline CLARITAS LONG SHORT FI MULTIMERCADO & $-4,48 \%$ & $-0,05 \%$ & $-2,36 \%$ & $-1,06 \%$ & $-12,55 \%$ \\
\hline CREDIT AGRICOLE LONG SHORT FI MULTIMERCADO & $-2,10 \%$ & $2,58 \%$ & $1,45 \%$ & $-1,78 \%$ & $-11,26 \%$ \\
\hline CREDIT SUISSE LONG SHORT EQUITIES FI MULTIMERCADO LP & $6,21 \% *$ & $12,01 \% *$ & $10,71 \% *$ & $2,63 \%$ & $-1,31 \%$ \\
\hline FAMA SHOOTER 60 FI AÇÕES & $-6,08 \%$ & $-0,88 \%$ & $21,41 \%$ & $-6,81 \%$ & $-27,48 \%$ \\
\hline FAMA SNIPER FI MULTIMERCADO LP & $-1,86 \%$ & $-0,29 \%$ & $10,05 \% *$ & $0,29 \%$ & $-14,53 \%$ \\
\hline FAMA STRIKER 28 FI MULTIMERCADO LP & $-2,93 \%$ & $1,69 \%$ & $12,06 \% *$ & $-2,08 \%$ & $-18,33 \%$ \\
\hline FATOR ARBITRAGEM FI MULTIMERCADO & $-0,75 \%$ & $0,52 \%$ & $1,88 \%$ & $0,37 \%$ & $-6,44 \%$ \\
\hline FATOR BALANCEADO FI MULTIMERCADO & $-0,36 \%$ & $0,49 \%$ & $0,63 \%$ & $0,89 \%$ & $-3,93 \%$ \\
\hline FIDES LONG SHORT FI MULTIMERCADO & $0,50 \%$ & $0,27 \%$ & $\mathbf{8 , 5 1 \% *}$ & $4,64 \%$ & $-8,97 \%$ \\
\hline FIDES LONG SHORT PLUS FI MULTIMERCADO & $3,12 \%$ & $5,14 \%$ & $21,99 \% *$ & $13,60 \%$ & $-19,21 \%$ \\
\hline FIDUCIA EQUITY HEDGE FI MULTIMERCADO & $-4,02 \%$ & $3,83 \%$ & $-0,17 \%$ & $-11,84 \%$ & $-12,51 \%$ \\
\hline FOCUS LONG SHORT FI MULTIMERCADO & $-0,41 \%$ & $5,89 \% *$ & $2,49 \%$ & $-1,91 \%$ & $-7,80 \%$ \\
\hline GAP LONG SHORT FI MULTIMERCADO & $2,68 \%$ & $\mathbf{9 , 5 2 \%} \%$ & $6,29 \% *$ & $0,91 \%$ & $-5,27 \%$ \\
\hline HG STRATEGY LONG SHORT FI MULTIMERCADO & $-1,62 \%$ & $6,05 \%$ & $9,96 \%$ & $1,20 \%$ & $-18,35 \%$ \\
\hline IB LONG SHORT EQUITIES FIC MULTIMERCADO & $-2,10 \%$ & $-0,55 \%$ & $0,89 \%$ & $-5,73 \%$ & $3,13 \%$ \\
\hline IP EQUITY HEDGE FI MULTIMERCADO & $-0,59 \%$ & $8,34 \%$ & $13,45 \% *$ & $-7,80 \%$ & $-13,23 \%$ \\
\hline ITAÚ EQUTTY HEDGE FI MULTIMERCADO & $-1,30 \%$ & $1,78 \%$ & $3,25 \%$ & $-6,53 \%$ & $-2,71 \%$ \\
\hline MANDARIM LONG SHORT 30 FI MULTIMERCADO & $-9,98 \%$ & $-25,32 \%$ & $-6,34 \%$ & $-8,51 \%$ & $0,81 \%$ \\
\hline MELLON LONG SHORT FI MULTIMERCADO & $-3,47 \%$ & $3,59 \%$ & $0,05 \%$ & $-2,69 \%$ & $-15,01 \%$ \\
\hline MODAL ARBITRAGEM PHOENIX FI MULTIMERCADO & $2,94 \%$ & $10,97 \%$ & $-3,71 \%$ & $6,39 \%$ & $-2,59 \%$ \\
\hline NEO LONG SHORT FI MULTIMERCADO & $1,81 \%$ & $3,30 \%$ & $1,90 \%$ & $-2,71 \%$ & $2,40 \%$ \\
\hline NEST MILE HIGH FI MULTIMERCADO & $0,82 \%$ & $4,30 \%$ & $4,53 \%$ & $-5,63 \%$ & $-6,48 \%$ \\
\hline POLO CSHG FIC ACCÕES & $8,37 \%$ & $6,53 \%$ & $0,45 \%$ & $-0,47 \%$ & $42,56 \% *$ \\
\hline POLO NORTE FI MULTIMERCADO & $2,37 \%$ & $2,05 \%$ & $0,54 \%$ & $0,00 \%$ & $9,60 \%$ \\
\hline RIO MARKET NEUTRAL FI MULTIMERCADO & $-0,56 \%$ & $1,00 \%$ & $1,19 \%$ & $3,04 \%$ & $-6,20 \%$ \\
\hline SAFRA LONG SHORT FI MULTIMERCADO & $-2,18 \%$ & $4,27 \%$ & $2,16 \%$ & $-7,17 \%$ & $-7,86 \%$ \\
\hline SULAMÉRICA LONG AND SHORT FI MULTIMERCADO & $0,21 \%$ & $5,04 \% *$ & $2,18 \% *$ & $-1,58 \%$ & $-4,75 \%$ \\
\hline SULAMÉRICA MULTICARTEIRA FI MULTIMERCADO & $-1,37 \%$ & $-0,80 \%$ & $1,89 \% *$ & $-3,83 \%$ & $-3,17 \%$ \\
\hline TATICA STRATEGY FI AÇÕES & $-0,87 \%$ & $5,46 \%$ & $-10,43 \%$ & $-7,56 \%$ & $-1,11 \%$ \\
\hline UBS PACTUAL ARBITRAGEM FI MULTIMERCADO & $-2,76 \%$ & $5,06 \%$ & $10,21 \% *$ & $-8,63 \%$ & $-13,43 \%$ \\
\hline UBS PACTUAL TOTAL RETURN EQUITIES FI MULTIMERCADO & $-6,48 \%$ & $4,53 \%$ & $7,96 \% *$ & $-4,48 \%$ & $-27,20 \%$ \\
\hline UNIBANCO ARBITRAGEM RV FIC MULTIMERCADO & $-1,26 \%$ & $-1,55 \%$ & $-0,13 \%$ & $-2,39 \%$ & $0,73 \%$ \\
\hline UNIFUND ARBITRAGEM PLUS FIC MULTIMERCADO & $0,01 \%$ & $1,23 \%$ & $4,11 \%$ & $1,92 \%$ & $0,77 \%$ \\
\hline VICTOIRE LONG SHORT V5 FI MULTIMERCADO & $-2,26 \%$ & $-3,64 \%$ & $1,36 \%$ & $-1,67 \%$ & $-6,84 \%$ \\
\hline VOTORANTIM EQUITY LONG SHORT FI MULTIMEI & $0,14 \%$ & $1,83 \%$ & $-1,83 \%$ & $3,70 \%$ & $-2,93 \%$ \\
\hline
\end{tabular}

$*$ Valores significativos e positivos $5 \%$ de significância Unicaudal $)$

\section{Conclusão}

O crescimento na última década na indústria de fundos no Brasil foi impressionante, principalmente quando avaliamos o crescimento dos fundos classificados como multimercados, como os Hegde Funds são classificados no Brasil. Contudo, esse crescimento levanta um questionamento sobre essa indústria: será que os Hegde Funds conseguem prover aos investidores retornos superiores ajustados ao risco para justificar tal crescimento do interesse dos investidores por esse tipo de veículo de investimento?

A metodologia utilizada nesse artigo permite avaliar a dependência dos retornos dos fundos em duas situações distintas. A primeira, por meio de estimações do CAPM convencional e a segunda com estimações do CAPM inserindo um componente de assimetria. Em ambas as situações utilizou-se o GMM, que leva em conta possíveis problemas de correlação serial e heterocesticidade. Em relação à primeira situação, encontramos que os fundos possuem uma dependência positiva aos retornos de mercado, em geral inferior a $10 \%$. Percebemos também que nem todos os fundos podem ser considerados totalmente neutros e, neste caso, 
seus retornos podem ser explicados por retornos de mercado. Foram encontradas evidências que existe um grupo de fundos Long-Short no Brasil que consegue capturar excesso de retorno. Assim, os gestores de alguns fundos conseguem prover aos investidores retornos superiores ajustados ao risco. Porém, poucos fundos foram capazes de prover esses retornos quando avaliamos esses fundos nos anos de 2006 e 2007 conjuntamente, bem como o período de março de 2007 até março de 2008.

Em relação à segunda situação, avaliamos se os fundos possuem market timing, o que caracterizaria uma assimetria em relação aos retornos de mercado. A evidência sugere que os gestores não possuem tal habilidade. No melhor dos casos, diríamos que pouquíssimos gestores possuem tal habilidade; embora, conforme mencionado, existam críticas a metodologia de Merton (1981) e Henriksson e Merton (1981).

Finalmente, fizemos uma análise de persistência do Alpha usando o modelo CAPM e as evidências sugerem que obter tal característica é bastante difícil. Para o período analisado na avaliação de persistência, nenhum gestor conseguiu prover investidores com excesso de retorno positivo em mais de dois sub-periodos (semestrais) consecutivos. Assim, os fundos não possuem persistência na geração de Alpha no período analisado.

A conclusão é que investidores devem ser cautelosos no momento de escolher fundos para alocar seus recursos, pois nem todos os fundos conseguem obter desempenhos interessantes. Um ponto que reforça a necessidade de investidores serem diligentes na escolha de seus gestores de investimento vem da avaliação da persistência do excesso de retornos que os fundos conseguem prover, pois os gestores não conseguem gerar persistência no Alpha.

A indústria de hedge funds no Brasil ainda é uma indústria em crescimento e em desenvolvimento. A quantidade e o período de informações disponíveis ainda são limitados. Um número limitado de fundos possui um histórico de retornos superior a 5 anos e a maioria dos fundos dessa categoria disponíveis no mercado possui em média 2 anos de histórico. Além disso, é importante ressaltar que o mercado (Ibovespa) apresentou rentabilidade positiva em quase todos os anos da amostra analisada. Assim novos estudos que estendam o período de investigação deste artigo podem ser interessantes para verificar as evidências aqui encontradas. Em especial, seria importante estudar mais períodos de baixa do mercado.

\section{Referências}

Anson, M. J. P. (2006). Handbook of Alternative Investments. John Wiley \& Sons, Inc.

Brito, N. R. O. (2003). Avaliação de desempenho e Market Timing: O índice de habilidade. Revista Brasileira de Finanças, 1:1-17.

Brown, S. J., Goetzmann, W. N., \& Park, J. M. (2001). Careers and survival: 
Competition and risk in the hedge fund and CTA industry. Journal of Finance, 56:1869-1886.

Campbell, J. Y., Lo, A. W., \& Mackinlay, A. C. (1997). The Econometrics of Financial Markets. Princeton University Press, Princeton, New Jersey.

Carhart, M. M., Carpenter, J. N., Lynch, A. W., \& Musto, D. K. (2002). Mutual fund survivorship. Review of Financial Studies, 15:149-1463.

Castro, B. R. \& Minardi, A. M. A. F. (2009). Comparação do desempenho dos fundos de ações ativos e passivos. Revista Brasileira de Finanças, 7:143-161.

Cuthbertson, K., Nitzsche, D., \& O'sullivan, N. (2006). The market timing ability of UK. Equity Mutual Funds. Working paper.

Fama, E. F. (1970). Efficient capital markets: A review of theory and empirical work. The Journal of Finance, pages 383-417.

Fung, W. \& Hsieh, D. A. (2002). The risks in fixed income hedge funds styles. Journal of Fixed Income, 12:6-27.

Fung, W. \& Hsieh, D. A. (2004). Extracting portable alphas from equity Long/Short hedge funds. Journal of Investment Management, 2:1-19.

Henriksson, R. D. (1984). Market timing and mutual fund performance: An empirical investigation. Journal of Business, 57:73-96.

Henriksson, R. D. \& Merton, R. C. (1981). On market timing and investment performance. II. statistical procedures for evaluating forecasting skills. Journal of Business, 54:513-533.

Ineichen, A. M. (2002). The alpha in fund of hedge funds: Do fund of hedge funds managers add value? Journal of Wealth Management, 5:8-25.

Jacobs, B. I. \& Levy, K. N. (1999). Long-short portfolio management an integrated approach. The Journal of Portfolio Management, 25:23-32.

Jiang, W. (2003). A nonparametric test of market timing. The Journal of Empirical Finance, 10:399-425.

Leusin, L. M. C. \& Brito, R. D. (2008). Market timing e avaliação de desempenho dos fundos brasileiros. Revista de Administração de Empresas, 48:22-36.

Liang, B. (1998). On the performance of hedge funds. Disponível em: http: //papers.ssrn.com/sol3/papers. cfm?abstract_id=89490.

Loomis, C. (1966). The Jones nobody keeps up with. Fortune Magazine, April:237-248. 
Markowitz, H. (1952). Portfolio selection. The Journal of Finance, 7:77-91.

Merton, R. C. (1981). On market timing and investment performance. I. an equilibrium theory of value for market forecasts. Journal of Business, 54:363-406.

Patton, A. J. (2004). Are 'market neutral' hedge funds really market neutral? Disponível em: http://papers.ssrn.com/sol3/papers.cfm?abstract_ id $=557096$.

Penna, A. L. d. A. (2007). Uma análise da estratégia long-short e a neutralidade dos fundos long-short brasileiros em relação ao Ibovespa. Dissertação-Mestrado. FGV - Escola de Pós-Graduação em Economia.

Schneeweis, T. \& Martin, G. (2000). The Benefits of Hedge Funds: Asset Allocation for the Institutional Investor. Lehman Brothers.

Schneeweis, T., Martin, G., \& Kazemi, H. B. (2003). Understanding hedge fund performance: Research issues revisited-part II. Journal of Alternative Investments, 5:8-30.

Sharpe, W. F. (1964). Capital asset prices: A theory of market equilibrium under conditions of risk. The Journal of Finance, 19:425-442.

Treynor, J. L. \& Mazuy, K. (1966). Can mutual funds outguess the market? Harvard Business Review, 44:131-136. 


\section{Apêndice}

\section{Avaliação do Desempenho dos Fundos Long-Short}

Tabela A.1

Avaliação da exposição dos fundos long-short em relação a Bolsa (Ibovespa médio)

\section{Fundo}

ABN AMRO STAR LONG SHORT FIC MULTIMERCADO ÁTICO LONG SHORT FI MULTIMERCADO

BANIF NITOR FI MULTIMERCADO

BNY MELLON ARX LONG AND SHORT FI MULTIMERCADO

BRADESCOLONG SHORT FI MULTIMERCADO

BRZLONG SHORT HUULTMERCADO

CREDIT AGRICOLE LONG SHORT FIMULTIMERCAD

CREDIT SUISSE LONG SHORT FQUTTIES FI MULTIMERCADO

FAMA SHOOTER 60 FI ACÕES

FAMA SNIPER FI MULTIMERCADO LP

FAMA STRIKER 28 FI MULTIMERCADO LP

FATOR ARBITRAGEM FI MULTIMERCADO

FATOR BALANCEADO FI MULTIMERCADO

FIDES LONG SHORT FI MULTIMERCADO

FIDES LONG SHORT PLUS FT MULTMERCADO

FOCUS LONG SHORT FI MULTIMERCADO

GAP LONG SHORT FI MULTMTECADO

HG STRATEGY LONG SHORT FI MULTIMERCADO

IB LONG SHORT EQUITIES FIC MULTIMERCADO

IP EQUITY HEDGE FI MULTIMERCADO

ITAÚ EQUITY HEDGE FI MULTIMERCADO

MANDARIM LONG SHORT 30 FT MULTMERCADO

MELLON LONG SHORT FI MULTIMERCADO

MODAL ARBITRAGEM PHOENIX FI MULTIMERCADO

NEO LONG SHORT FI MULTIMERCADO

POLO CSHG FIC AÇÕES

POLO NORTE FI MULTIMERCADO

RIO MARKET NEUTRAL FI MULTIMERCADO

SAFRA LONG SHORT FI MULTIMERCADO

SULAMÉRICA LONG AND SHORT FI MULTIMERCADO

SULAMERICA MULTICARTEIRA FI MULTIMERCADO

TATICA STRATEGY FI AÇÕES

UBS PACTUAL TOTAL RETURN EQUITIES FI MULTIMERCADO

UNIBANCO ARBITRAGEM RV FIC MULTIMERCADO

UNIFUND ARBITRAGEM PLUS FIC MULTIMERCAD

VOTORANTIM EQUTY LONG SHORT FI MULTIMERCADO

\begin{tabular}{|c|c|c|c|c|c|}
\hline \multicolumn{6}{|c|}{ GMM } \\
\hline \multicolumn{2}{|c|}{ CAPM } & \multicolumn{3}{|c|}{ CAPM + Assimetria } & $T_{T}$ \\
\hline Alpha $(\alpha)^{*}$ & Beta $(\beta)$ & Alpha $(\alpha)^{*}$ & Beta $(\beta)$ & $\operatorname{Gama}(\gamma)$ & \\
\hline$-0,76 \%$ & $5,43 \% *$ & $11,39 \% *$ & $1,22 \%$ & $-7,84 \%$ & 497 \\
\hline$-0.59 \%$ & $1,56 \%$ & $2.35 \%$ & $0,49 \%$ & $-1,98 \%$ & 497 \\
\hline$-0,49 \%$ & $2,34 \% *$ & $1,38 \%$ & 1,66\%* & $-1,27 \%$ & 497 \\
\hline$-1,86 \%$ & $2,12 \% *$ & $2,02 \%$ & $0,71 \%$ & $-2,63 \%$ & 497 \\
\hline $2,46 \%$ & $3,82 \% *$ & $18,06 \% *$ & $-1,34 \%$ & $-9,62 \%$ & 497 \\
\hline $0,30 \%$ & $2,09 \% *$ & $4,22 \% *$ & $0,69 \%$ & $-2,61 \%$ & 497 \\
\hline $1.59 \% *$ & $0.57 \% *$ & $3,43 \%^{*}$ & $-0,09 \%$ & $-1,23 \%$ & 497 \\
\hline$-4,48 \%$ & $10,12 \% *$ & $6,80 \%$ & $6,05 \% *$ & $-7,58 \%$ & 497 \\
\hline$-2,10 \%$ & $1,81 \% *$ & $9,47 \% *$ & $-2,26 \% *$ & $-7,59 \%$ & 497 \\
\hline $6,21 \% *$ & $1,98 \% *$ & $2,39 \%$ & $3,32 \% *$ & $2,49 \%$ & 497 \\
\hline$-6,08 \%$ & $-1,79 \%$ & $35,83 \% *$ & $-15,24 \% *$ & $-25,07 \%$ & 497 \\
\hline$-1,86 \%$ & $-3,09 \% *$ & $16,35 \% *$ & $-9,29 \% *$ & $-11,56 \%$ & 497 \\
\hline$-2,93 \%$ & $-2,48 \%$ & $23,04 \% *$ & $-11,12 \% *$ & $-16,11 \%$ & 497 \\
\hline$-0,75 \%$ & $4,37 \% *$ & $4,59 \%$ & $2,46 \%$ & $-3,56 \%$ & 497 \\
\hline$-0,36 \%$ & $2,60 \% *$ & $1,94 \%$ & $1,77 \% *$ & $-1,55 \%$ & 497 \\
\hline $0,50 \%$ & $1,46 \%$ & $11,11 \% *$ & $-2,20 \% *$ & $-6,82 \%$ & 497 \\
\hline $3,12 \%$ & 2,90 & $29,39 \% *$ & $-5,37 \% *$ & $-15,42 \%$ & 497 \\
\hline$-4,02 \%$ & $13,86 \% *$ & $4,96 \%$ & $10,60 \% *$ & $-6,08 \%$ & 497 \\
\hline$-0,41 \%$ & $1,52 \% *$ & $4,04 \%$ & $-0,08 \%$ & $-2,97 \%$ & 497 \\
\hline $2,68 \%$ & $2,05 \% *$ & $10,13 \% *$ & $-0,51 \%$ & $-4,76 \%$ & 497 \\
\hline$-1,62 \%$ & $21,67 \% *$ & $32,99 \% *$ & $10,68 \% *$ & $-20,48 \%$ & 497 \\
\hline$-2,10 \%$ & $-1,12$ & $1,39 \%$ & $-2,40$ & $-2,38 \%$ & 497 \\
\hline$-0,59 \%$ & $5,72 \% *$ & $10,24 \% *$ & $1,95 \%$ & $-7,03 \%$ & 497 \\
\hline$-1,30 \%$ & $-0,47 \%$ & $3,17 \%$ & $-2,08 \%$ & $-3,00 \%$ & 497 \\
\hline$-9,98 \%$ & $32,11 \% *$ & $3,49 \%$ & $27,03 \% *$ & $-9,47 \%$ & 497 \\
\hline$-3,47 \%$ & 2,44 & $9,99 \% *$ & $-2,32 \%$ & $-8,87 \%$ & 497 \\
\hline $2,94 \%$ & 4,049 & $4,93 \%$ & 3,34 & $-1,30 \%$ & 497 \\
\hline $1,81 \%$ & 1,77 & $8,07 \% *$ & $-0,4$ & $-4,05 \%$ & 497 \\
\hline $0,82 \%$ & $2,58 \%$ & $2,23 \%$ & $2,08 \%$ & $-0,94 \%$ & 497 \\
\hline $8,37 \%$ & $-5,2$ & 28,94 & $-11,54 \% *$ & -11, & 497 \\
\hline $2,37 \%$ & $1,06 \%$ & $10,46 \% *$ & $-1,71 \%$ & $-5,16 \%$ & 497 \\
\hline$-0,56 \%$ & $0,93 \%$ & $8,53 \% *$ & $-2,26 \%$ & $-5,95 \%$ & 497 \\
\hline$-2,18 \%$ & 0,60 & 9,19 & $-3,4$ & $-7,4$ & 497 \\
\hline $0,21 \%$ & $2,22 \% *$ & $3,72 \%$ & $0,97 \%$ & $-2,34 \%$ & 497 \\
\hline$-1,37 \%$ & $5,72 \%$ & $3,28 \%$ & $4,05 \% *$ & $-3,12 \%$ & 497 \\
\hline$-0,87 \%$ & 22,46 & $7,45 \%$ & 19,53 & $-5,4$ & 497 \\
\hline-2, & 131. & $8,92 \%$ & & -7, & 497 \\
\hline$-6,48 \%$ & & & & -9 , & 497 \\
\hline$-1,26 \%$ & 0,8 & $4,59 \%$ & $-1,26 \%$ & $-3,91 \%$ & 497 \\
\hline $0,01 \%$ & $2,37 \%$ & $9,80 \% *$ & $-1,03 \%$ & $-6,33 \%$ & 497 \\
\hline$-2,26 \%$ & $6.74 \% *$ & $17,70 \% *$ & $-0,03 \%$ & $-12,62 \%$ & 497 \\
\hline $0,14 \%$ & $2,59 \% *$ & $1,59 \%$ & $2,06 \%$ & $-0,98 \%$ & \\
\hline
\end{tabular}

